\title{
Paclitaxel reduces formation of hypertrophic scars in the rabbit ear model
}

\author{
This article was published in the following Dove Press journal: \\ Therapeutics and Clinical Risk Management \\ 27 July 2015 \\ Number of times this article has been viewed
}

\author{
Li-ping Huang ${ }^{1, *}$ \\ Guo-qi Wang',* \\ Zi-shan Jia' \\ Jing-wen Chen' \\ Gang Wang' \\ Xing-lin Wang' \\ 'Department of Physical Therapy, \\ 2Department of Orthopedics, Chinese \\ PLA General Hospital, Beijing, \\ People's Republic of China \\ *These authors contributed equally \\ to this work
}

\begin{abstract}
Background and objective: The onset and progression of pathological scarring involves multiple cytokines and complex mechanisms. However, hyperplasia of fibroblasts and neovascularization plays important roles, which can be inhibited by paclitaxel. The aim of this study was to investigate the efficacy of paclitaxel in the treatment of hypertrophic scars on rabbit ears.

Methods: Rabbit ear models of hypertrophic scars were established to observe the therapeutic effects of paclitaxel at different concentrations (12 mg/L, $24 \mathrm{mg} / \mathrm{L}, 48 \mathrm{mg} / \mathrm{L}, 96 \mathrm{mg} / \mathrm{L}, 18 \mathrm{mg} / \mathrm{L}$, $54 \mathrm{mg} / \mathrm{L}, 162 \mathrm{mg} / \mathrm{L}, 486 \mathrm{mg} / \mathrm{L}, 30 \mathrm{mg} / \mathrm{L}, 150 \mathrm{mg} / \mathrm{L}, 750 \mathrm{mg} / \mathrm{L}, 3,750 \mathrm{mg} / \mathrm{L})$. The outcome measures included hypertrophic index (HI), density of fibroblasts, density of collagenous fibers, and microvessel density.

Results: In comparison with the control group, the concentrations of $96 \mathrm{mg} / \mathrm{L}, 150 \mathrm{mg} / \mathrm{L}$, and $162 \mathrm{mg} / \mathrm{L}$ significantly reduce the formation of hypertrophic scars in the rabbit ear models. However, local necrosis was found in the rabbit ear models treated with paclitaxel solution $>400 \mathrm{mg} / \mathrm{L}$.

Conclusion: Paclitaxel has strong inhibitory effects on the hyperplasia of fibroblasts, deposition of collagen, and microangiogenesis in hypertrophic scars on rabbit ears within the concentration range from $48 \mathrm{mg} / \mathrm{L}$ to $162 \mathrm{mg} / \mathrm{L}$, without causing local necrosis.
\end{abstract}

Keywords: hypertrophic scar, paclitaxel, rabbit ear model

\section{Introduction}

Following burns, traumatic injuries, and surgical procedures, hypertrophic scarring is associated with the hyperplasia of fibroblasts, the abnormal synthesis and degradation of extracellular matrix, the disorders in regulatory cytokines, and abnormal neovascularization. ${ }^{1,2}$ Paclitaxel is an antineoplastic agent extracted from Taxus cells. Past reports have shown that paclitaxel reduces the hyperplasia of fibroblasts and neovascularization. ${ }^{3}$ In this study, we applied different concentrations of paclitaxel solution to the rabbit ear scar models by injection and observed the effects of paclitaxel on scar tissues, evaluating the efficacy of paclitaxel in the treatment of hypertrophic scars and investigating the optimum dosage.

\section{Materials and methods}

\section{Reagents and animals}

This study was carried out after getting the permission and approval from the Animal Care and Use Committee at Chinese PLA General Hospital. All the animals were housed in individual cages under constant temperature $\left(22^{\circ} \mathrm{C}\right)$ and humidity $(45 \%)$ with a 12-hour light-dark cycle. A total of 18 Japanese white rabbits were used for this study.

The reagents used in this study were as follows: 1) paclitaxel injection (Corden Pharma Latina S.P.A., Sermoneta LT, Italy); 2) hematoxylin and eosin; 3) Sirius
Correspondence: Xing-lin Wang Department of Physical Therapy, Chinese PLA General Hospital, No 28 Fuxing Road, Beijing 100853, People's Republic of China

Tel +86 I52 10889919

Fax +86 I0 6693755 I

Email wangxI30I@I26.com
Therapeutics and Clinical Risk Management 20 I5:I I 1089-1095 (c) (1) (5) 2015 Huang et al. This work is published by Dove Medical Press Limited, and licensed under Creative Commons Attribution - Non Commercial (unported, v3.0) BY NC License. The full terms of the License are available at http://creativecommons.org/licenses//by-nc/3.0/. Non-commercial uses of the work are permitted without any further

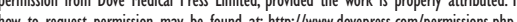
how to request permission may be found at: http://www.dovepress.com/permissions.php 
red staining kit; 4) acid fuchsin and aniline blue and; 5) 18 Japanese white rabbits, with unwounded ears and a body weight range from $2.0 \mathrm{~kg}$ to $2.5 \mathrm{~kg}$.

\section{Establishment of animal models of hypertrophic scars}

The rabbits were anesthetized with intramuscular injection of a ketamine $(40 \mathrm{mg} / \mathrm{kg})$ and Xylazine $(5 \mathrm{mg} / \mathrm{kg})$ mixture before surgery. The ventral side of ears was unhaired, disinfected with $70 \%$ ethanol and draped. For each rabbit, four full-thickness wound surfaces $(1.5 \mathrm{~cm} \times 1.5 \mathrm{~cm})$ were made on the left and right sides of the midline of the ventral side of the ears, the perichondrium was scraped, and the cartilage was reserved. ${ }^{4}$ Then, all the wounds were dressed with sterile gauzes. A total of 144 wound surfaces were made in 36 rabbit ears and bandaged. On the second day after operation, the dressings were removed and the wound surfaces were exposed to heal spontaneously, detailed in Figure 1.

\section{Preparation of paclitaxel solution and grouping}

The paclitaxel injection $(6,000 \mathrm{mg} / \mathrm{L})$ was diluted with normal saline $0.9 \%$ infusion into the following concentrations of solution: 1) $12 \mathrm{mg} / \mathrm{L}, 24 \mathrm{mg} / \mathrm{L}, 48 \mathrm{mg} / \mathrm{L}$, and $96 \mathrm{mg} / \mathrm{L}$ (baseline concentration of $6 \mathrm{mg} / \mathrm{L}$, concentration gradient of 2×);2) $18 \mathrm{mg} / \mathrm{L}, 54 \mathrm{mg} / \mathrm{L}, 162 \mathrm{mg} / \mathrm{L}$, and $486 \mathrm{mg} / \mathrm{L}$ (baseline concentration of $6 \mathrm{mg} / \mathrm{L}$, concentration gradient of $3 \times$ ); and 3) $30 \mathrm{mg} / \mathrm{L}, 150 \mathrm{mg} / \mathrm{L}, 750 \mathrm{mg} / \mathrm{L}$, and $3,750 \mathrm{mg} / \mathrm{L}$ (baseline concentration of $6 \mathrm{mg} / \mathrm{L}$, concentration gradient of $5 \times$ ). The baseline group was $6 \mathrm{mg} / \mathrm{L}$. The control group was $0.9 \%$ normal saline. There were 14 groups in all.

\section{Administration and biopsy}

Each rabbit had a total of eight scars in the ears. The control groups were injected with normal saline $0.9 \%$ infusion and the other groups were injected with different concentrations of

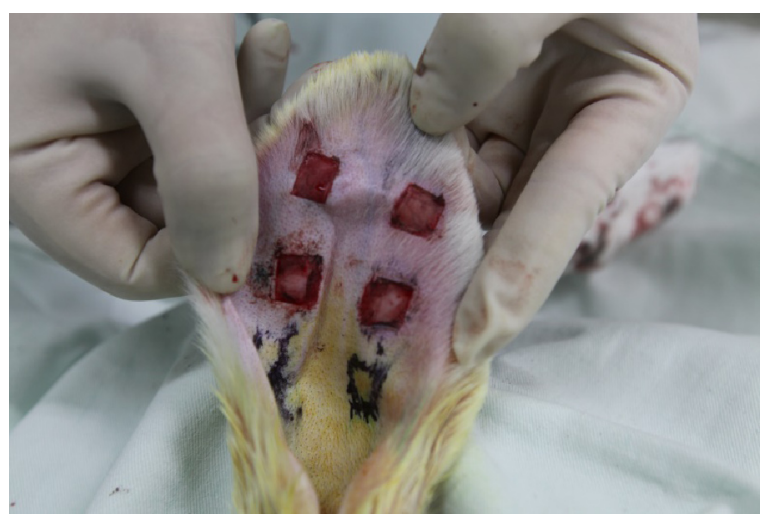

Figure I Establishment of rabbit ear model of hypertrophic scar. paclitaxel solutions, respectively. Each group had ten scars in all. The time of injection after wounding was at postoperative day 28 , because rabbit ear scar formation peaked at this time. The administration method was as follows: $1 \mathrm{~mL}$ syringe was used to inject the scar at three to five sites locating in the basal part of the edges with the inserting direction toward the center of scars; simultaneously, the needle was gradually inserted and the solution was gradually injected; after the injection was complete, the injection sites were compressed for 1-2 minutes to avoid leakage. A total of $0.8 \mathrm{~mL}$ of paclitaxel solution was injected into each scar. In order to attain sufficient absorption, pressure would be placed on the scar approximately 1-2 minutes. Ten days after injection, the samples were collected from the scars with sterile scalpel, fixed with methanol for 48 hours, and embedded with paraffin.

\section{Measurement of hypertrophic index (HI)}

The HE-stained tissue sections were measured with a micrometer under low-power lens, and the values of $\mathrm{HI}$ were calculated with the equation as follows: $\mathrm{HI}=A / B$ ( $A$ is defined as the vertical distance between the highest point of scar and the surface of cartilage, while $B$ is defined as the vertical distance between the level of normal skin and the surface of cartilage).

\section{Density of fibroblasts}

HE-stained tissue sections were observed under light microscope (400×) using Lumenera Infinity 2-1 CCD camera. Finding the thickest part of scar tissue, we selected six nonoverlapping fields of view, including three in the superficial part and three in the deep part; finding the edges of scar tissue, we selected two nonoverlapping fields on each side. Thus, a total of ten fields of view were selected. Each field of view was divided into some parallel grids, where the fibroblasts were calculated. The average value of the numbers of fibroblasts in all the ten fields of view was considered to be the density of fibroblasts.

\section{Density of collagenous fibers}

Sirius red stained tissue sections were observed under light microscope $(400 \times)$. Ten fields of view were randomly selected, respectively, in the superficial part, the deep part, and each side of scar tissues. Computer-aided pathology analysis system was used to calculate the density of stained collagen, and the average value was obtained.

\section{Microvessel density}

HE-stained tissue sections were observed under light microscope (400×), and the fields with rich microvessels were selected. The average value of the amounts of the microvessels 
in five fields of view was considered to be the microvessel density (the blood vessels whose diameters were more than eight times as large as one erythrocyte were excluded).

\section{Statistical analysis}

The database was established with Excel 2003. SPSS 16.0 for windows was used for statistical analysis. The measurement data were expressed as mean \pm SD and compared among the groups with one-way ANOVA; for post hoc multiple comparisons, least significant difference test was used with equal variances assumed, and Dunnett's T3 test was used with equal variances not assumed. $P<0.05$ was considered statistically significant.

\section{Results}

Due to serious necrosis on scars, three groups were excluded (groups with concentrations of $486 \mathrm{mg} / \mathrm{L}, 750 \mathrm{mg} / \mathrm{L}$, and $3,750 \mathrm{mg} / \mathrm{L}$ ). Eventually, eleven groups were included into statistical analysis.

\section{HE-staining}

The control group: a considerable amount of fibroblasts were found in the scar tissues, with a relatively large cell size, rich microvessels, and inflammatory infiltration; in the superficial layer of scar tissues, dense and irregularly arranged collagenous fibers were found, most of which were type I collagen; in the deep layer of scar tissues, linear and irregularly arranged collagenous fibers were found, which were longer than those in the superficial layer (Figure 2A). Paclitaxel group $(162 \mathrm{mg} / \mathrm{L})$ : the number of fibroblasts decreased after treatment, with linear and loose collagenous fibers; the amount of microvessels decreased after treatment (Figure 2B).

\section{Trichrome staining}

The control group: the scar tissues were relatively thick, with rich microvessels and collagenous fibers (Figure 3A).
Paclitaxel group: the scar tissues were smooth with decreased microvessels and less dense collagenous fibers in comparison with the control group (Figure 3B).

\section{The effects of paclitaxel in different concentrations}

Local necrosis was found in the rabbit ear models treated with paclitaxel solution $>400 \mathrm{mg} / \mathrm{L}$. In comparison with the control group, the concentrations of $96 \mathrm{mg} / \mathrm{L}, 150 \mathrm{mg} / \mathrm{L}$, and $162 \mathrm{mg} / \mathrm{L}$ significantly reduce the formation of hypertrophic scars in the rabbit ear models $(P<0.05)$. There was a significant decrease in the density of fibroblasts and collagenous fibers in the scars treated with paclitaxel solution of $96 \mathrm{mg} / \mathrm{L}$ or higher when compared with the control group $(P<0.05$, ten wounds for each group). There was a significant decrease in microvessel density in the scars treated with paclitaxel solution of $48 \mathrm{mg} / \mathrm{L}$ or higher when compared with the control group ( $P<0.05$, ten wounds for each group), detailed in Figures 4-7.

\section{Discussion}

The formation of hypertrophic scars is a complex biological process involving hyperplasia of fibroblasts, deposition and disorganization of collagen in the extracellular matrix, and impaired absorption of damaged tissues..$^{5-9}$ Generally, the experimental research on scarring can be divided into three types: cell culture in vitro, animal models, and clinical observation. For cell culture in vitro, fibroblasts are collected from the pathological scar tissues, cultured and subcultured in vitro, and subjected to different research-related interventions; the limitations of this research method lie in the prominent difference between in vivo and in vitro environments, which leads to biases in research results. For clinical observations, the collection of cases is sometimes too difficult to complete, although this research method makes it possible for the researchers to apply research-related interventions to
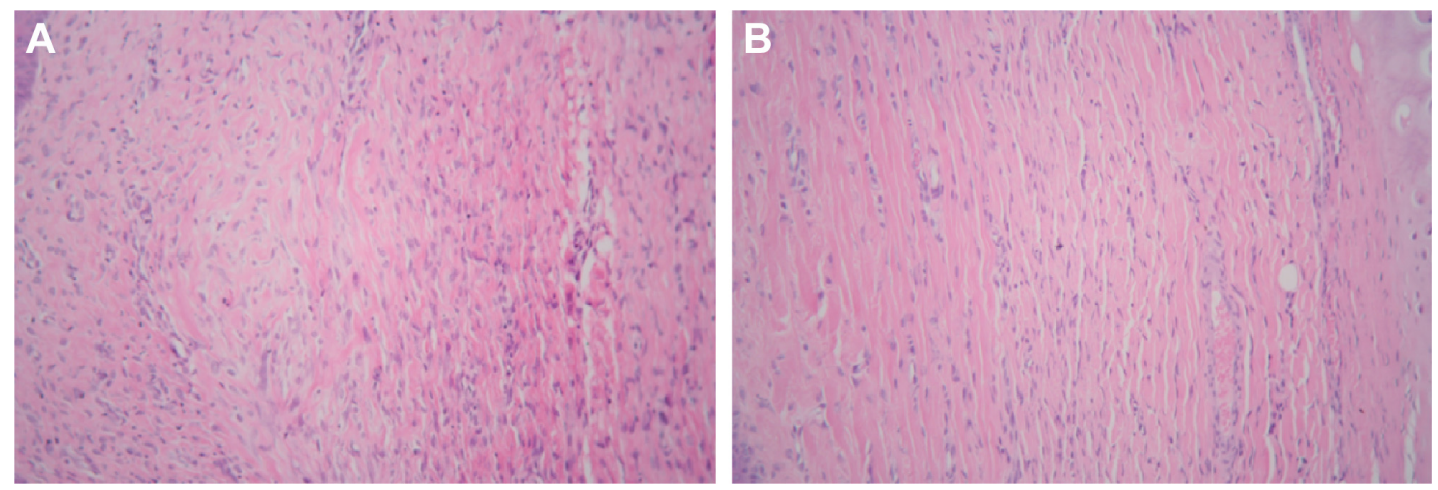

Figure 2 Comparison of control group (A) versus treatment group (B): fibroblasts, collagen, and blood vessels in scar tissue (HE staining, 200x). Abbreviation: $\mathrm{HE}$, hematoxylin and eosin. 

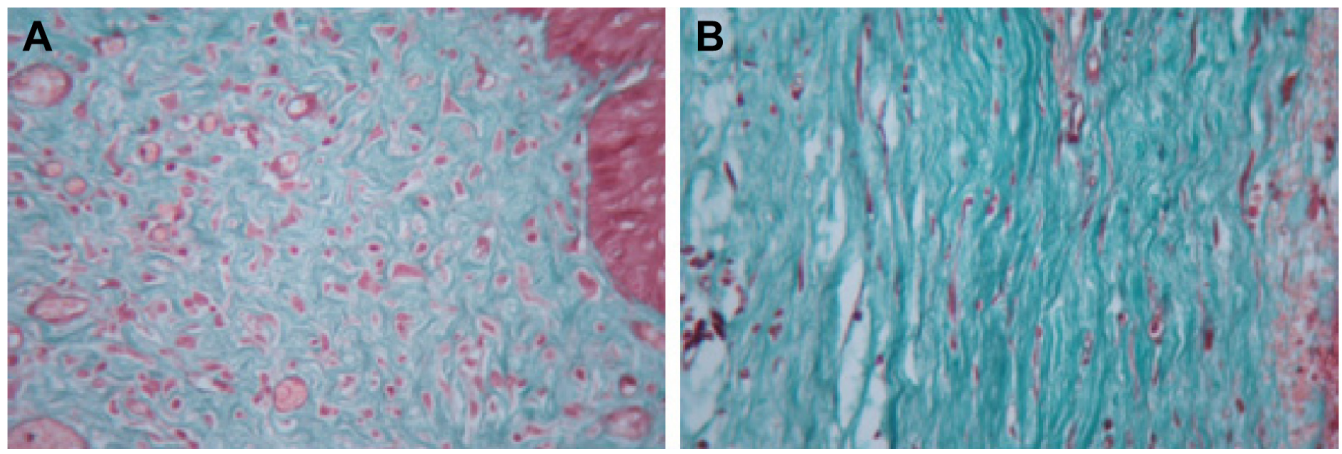

Figure 3 Comparison of control group (A) versus treatment group (B): collagen in scar tissue (Masson trichrome staining, 400×).

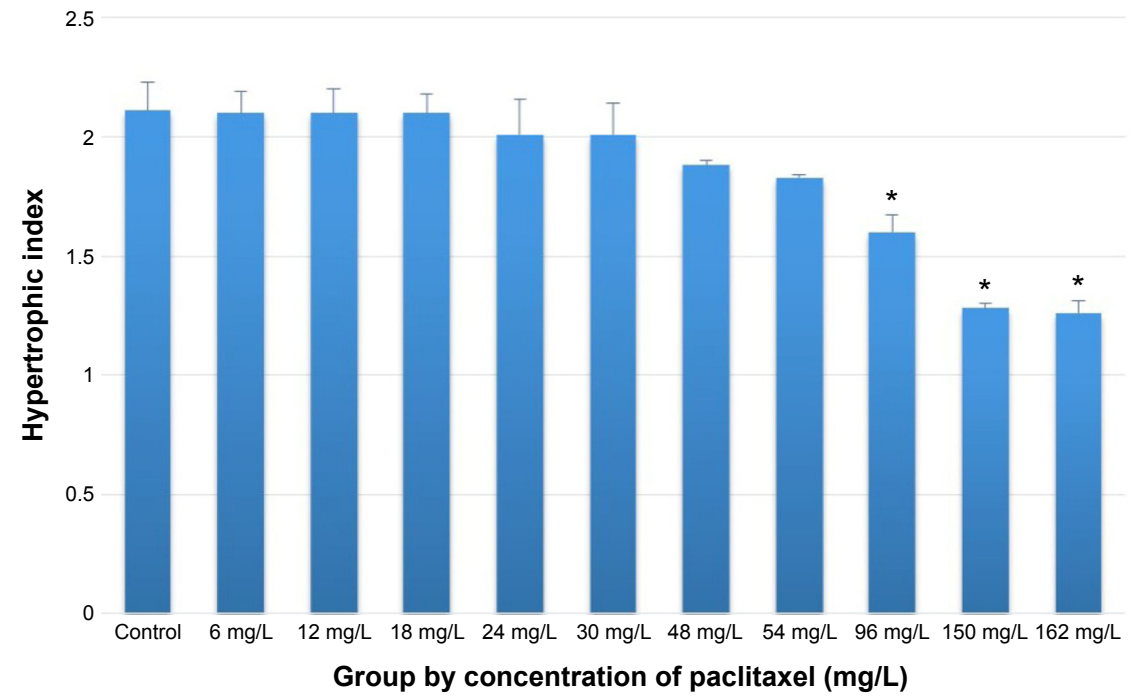

Figure 4 After treatment of hypertrophic scars with different concentrations of paclitaxel, there was a significant decrease in $\mathrm{HI}$ in the scars treated with paclitaxel solution of $96 \mathrm{mg} / \mathrm{L}$ or higher comparing with the control group.

Notes: $* \mathrm{P}<0.05, \mathrm{~N}=10$.

Abbreviation: $\mathrm{HI}$, hypertrophic index.

25

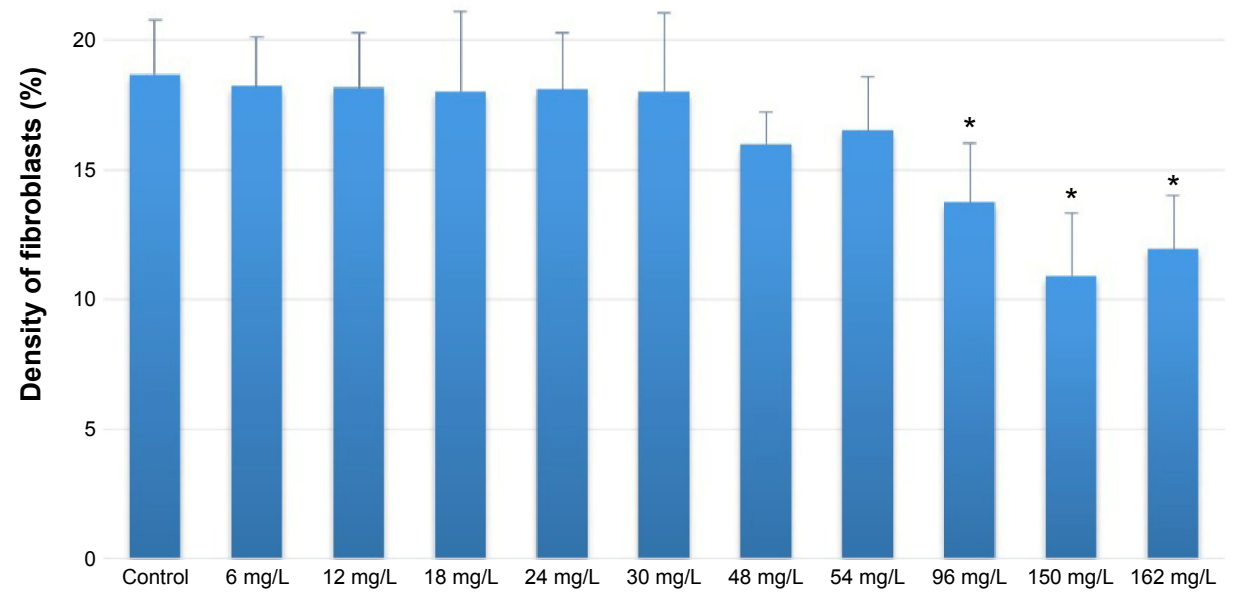

Group by concentration of paclitaxel (mg/L)

Figure 5 After treatment of hypertrophic scars with different concentrations of paclitaxel, there was a significant decrease in the density of fibroblasts in the scars treated with paclitaxel solution of $96 \mathrm{mg} / \mathrm{L}$ or higher comparing with the control group.

Notes: $* P<0.05, N=10$. 


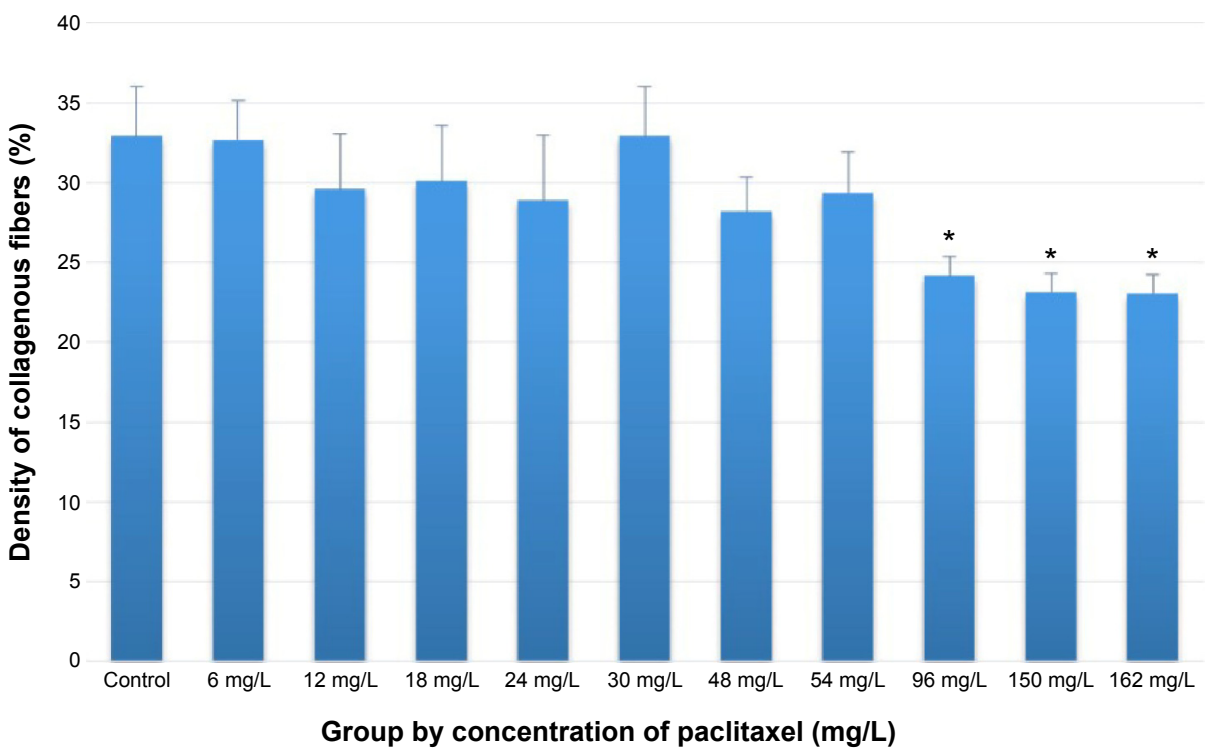

Figure 6 After treatment of hypertrophic scars with different concentrations of paclitaxel, there was a significant decrease in the density of collagenous fibers in the scars treated with paclitaxel solution of $96 \mathrm{mg} / \mathrm{L}$ or higher comparing with the control group.

Notes: $* P<0.05, \mathrm{~N}=10$.

the pathological scar tissues directly and obtain the most reliable data. Thus, many past reports regarding the new drugs and therapies in the treatment of pathological scarring were based on animal models.

The most commonly used animal models of scarring include nude mouse models and rabbit ear models. ${ }^{10-13}$ However, rejection response is always an avoidable problem in the establishment of nude mouse models, which involves the transplantation of human scar tissues. The rabbit ear model of scarring has much in common with human scars, such as the repair of wound surface and the histopathological structure.
Thus, we used rabbit ear models of scarring to investigate the effects of paclitaxel in the treatment of hypertrophic scars.

We applied different concentrations of paclitaxel to the scar tissues on the ventral side of the rabbit ear by local injection, observing the efficacy and concentration dependence of paclitaxel in the treatment of hypertrophic scars. Paclitaxel has been commonly used in clinics as an antineoplastic agent. Paclitaxel can enter the target cells and bind with the intracellular microtubule networks, increasing the assembly of microtubules, inhibiting the normal physiological disassembly of microtubules, and eventually inducing

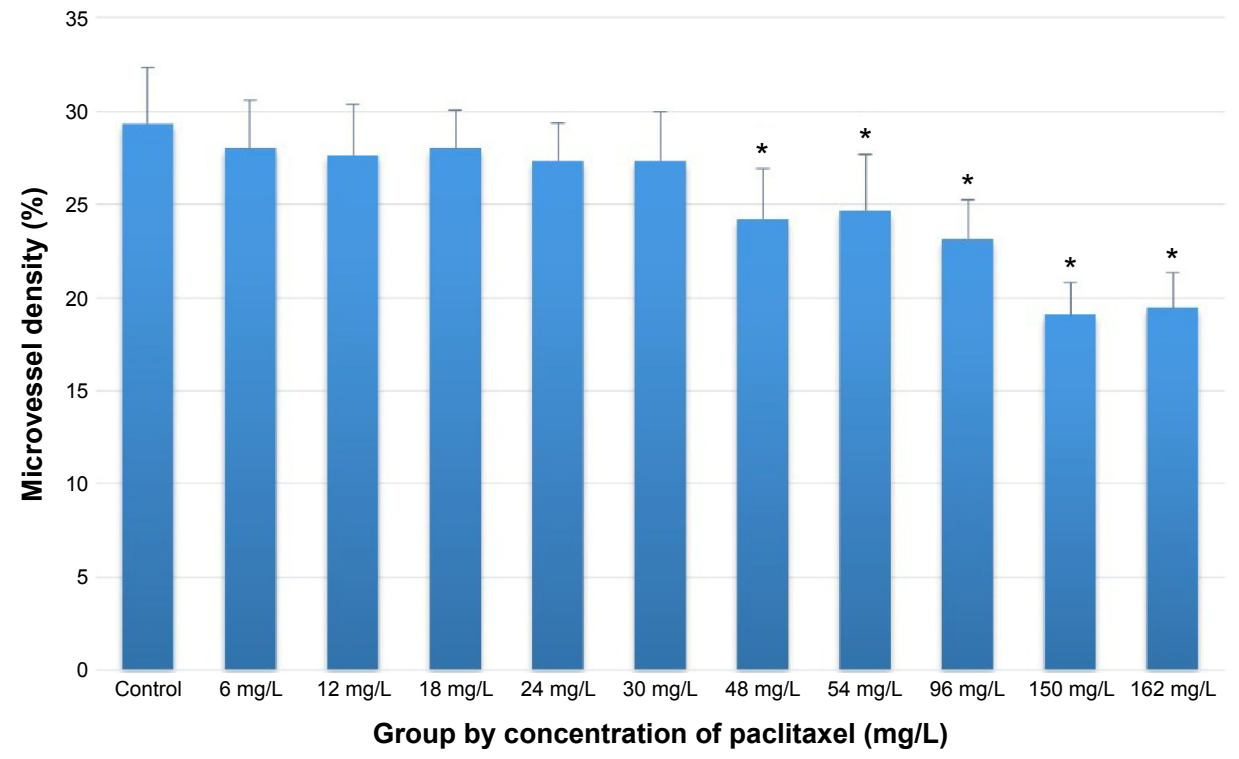

Figure 7 After treatment of hypertrophic scars with different concentrations of paclitaxel, there was a significant decrease in microvessel density in the scars treated with paclitaxel solution of $48 \mathrm{mg} / \mathrm{L}$ or higher comparing with the control group. Notes: $* P<0.05, \mathrm{~N}=10$. 
cell apoptosis. ${ }^{14}$ In addition, paclitaxel has inhibitory effects on the synthesis of collagen, hyperplasia of fibroblasts, and neovascularization. ${ }^{15,16}$

In our study, we found that the hypertrophy index of scars in the rabbit ear model increased as the concentration of paclitaxel decreased within the range from $48 \mathrm{mg} / \mathrm{L}$ to $162 \mathrm{mg} / \mathrm{L}$ and that the scars treated with paclitaxel showed no infiltration of inflammatory cells, with decreased density of fibroblasts and a considerable number of apoptotic cells. However, prominent infiltration of inflammatory cells was found in the controls, with a significantly higher density of fibroblasts and a great number of irregular and hyperchromatic fibroblasts. Obviously, our results support the argument that paclitaxel has direct inhibitory effects on the growth and proliferation of fibroblasts, which has been suggested in the existing literature. ${ }^{3}$

In the formation of pathological scars, collagen plays the essential role as the supporting structure. ${ }^{17}$ In our study, we found that the collagenous fibers were thick, irregularly arranged, and circlewise twisted in the controls. However, the collagenous fibers were thin and regularly arranged in the treated scar tissues, with a significantly lower density than that in the controls.

The growth of scar tissues requires neovascularization, which guarantees sturdy structure and adequate blood supply. Paclitaxel has an antineovascularization effect and inhibits the formation of pathological scars. In our study, we found that the treated scar tissues had a significantly lower microvessel density than that of the controls, presenting with prominent atrophy when the concentration of paclitaxel was $48 \mathrm{mg} / \mathrm{L}$ or high.

In visual inspection, we found that paclitaxel injection within the range from $48 \mathrm{mg} / \mathrm{L}$ to $162 \mathrm{mg} / \mathrm{L}$ had not only reduced the scar hyperplasia in rabbit ear models but also caused little damage to the surface of scars without ulcers and necrosis.

\section{Conclusion}

As stated above, paclitaxel has strong inhibitory effects on the hyperplasia of fibroblasts, deposition of collagen, and microangiogenesis in hypertrophic scars on rabbit ears within the concentration range from $48 \mathrm{mg} / \mathrm{L}$ to $162 \mathrm{mg} / \mathrm{L}$, without causing local necrosis. It might be possible to use paclitaxel in the treatment of pathological scars.

\section{Disclosure}

The authors report no conflicts of interest in this work.

\section{References}

1. Choi J, Lee EH, Park SW, Chang H. Regulation of transforming growth factor $\beta 1$, platelet-derived growth factor, and basic fibroblast growth factor by silicone gel sheeting in early-stage scarring. Arch Plast Surg. 2015;42(1):20-27.

2. O'Leary R, Wood EJ, Guillou PJ. Pathological scarring: strategic interventions. Eur J Surg. 2002;168:523-534.

3. Choritz L, Grub J, Wegner M, Pfeiffer N, Thieme H. Paclitaxel inhibits growth, migration and collagen production of human Tenon's fibroblasts - potential use in drug-eluting glaucoma drainage devices. Graefes Arch Clin Exp Ophthalmol. 2010;248(2):197-206.

4. Morris DE, Wu L, Zhao LL, et al. Acute and chronic animal models for excessive dermal scarring: quantitative studies. Plast Reconstr Surg. 1997;100(3):674-681.

5. Song C. Hypertrophic scars and keloids in surgery: current concepts. Ann Plast Surg. 2014;73(suppl 1):S108-S118.

6. Stoddard FJ Jr, Ryan CM, Schneider JC. Physical and psychiatric recovery from burns. Surg Clin North Am. 2014;94(4):863-878.

7. Tredget EE, Levi B, Donelan MB. Biology and principles of scar management and burn reconstruction. Surg Clin North Am. 2014; 94(4):793-815.

8. Gold MH, Berman B, Clementoni MT, Gauglitz GG, Nahai F, Murcia C. Updated international clinical recommendations on scar management: part 1 - evaluating the evidence. Dermatol Surg. 2014;40(8):817-824.

9. Gold MH, McGuire M, Mustoe TA, et al; International Advisory Panel on Scar Management. Updated international clinical recommendations on scar management: part 2 - algorithms for scar prevention and treatment. Dermatol Surg. 2014;40(8):825-831.

10. Wang J, Ding J, Jiao H, et al. Human hypertrophic scar-like nude mouse model: characterization of the molecular and cellular biology of the scar process. Wound Repair Regen. 2011;19(2):274-285.

11. Wu JG, Wei YJ, Ran X, Zhang H, Nian H, Qin LP. Inhibitory effects of essential oil from rhizomes of Ligusticum chuanxiong on hypertrophic scarring in the rabbit ear model. Pharm Biol. 2011;49(7):764-769.

12. Yagmur C, Guneren E, Kefeli M, Ogawa R. The effect of surgical denervation on prevention of excessive dermal scarring: a study on rabbit ear hypertrophic scar model. J Plast Reconstr Aesthet Surg. 2011; 64(10):1359-1365.

13. Kimura T. Hairless descendants of Mexican hairless dogs: an experimental model for studying hypertrophic scars. J Cutan Med Surg. 2011; 15(6):329-339.

14. Samarakoon R, Higgins CE, Higgins SP, Higgins PJ. Differential requirement for MEK/ERK and SMAD signaling in PAI-1 and CTGF expression in response to microtubule disruption. Cell Signal. 2009;21: 986-995.

15. Belotti D, Vergani V, Drudis T, et al. The microtubule-affecting drug paclitaxel has antiangiogenic activity. Clin Cancer Res. 1996;2(11): 1843-1849.

16. Will TA, Polcari AJ, Garcia JG, et al. Paclitaxel inhibits ureteral smooth muscle cell proliferation and collagen production in the absence of cell toxicity. J Urol. 2011;185(1):335-340.

17. Robson MC, Barnett RA, Leitch IO, Hayward PG. Prevention and treatment of post-burn scars and contracture. World J Surg. 1993;16(1):87-96. 
Therapeutics and Clinical Risk Management

Dovepress

\section{Publish your work in this journal}

Therapeutics and Clinical Risk Management is an international, peerreviewed journal of clinical therapeutics and risk management, focusing on concise rapid reporting of clinical studies in all therapeutic areas outcomes, safety, and programs for the effective, safe, and sustained use of medicines. This journal is indexed on PubMed Central, CAS,

Base, Scopus and the Elsevier Bibliographic databases. The manuscript management system is completely online and includes a very quick and fair peer-review system, which is all easy to use. Visit http://www.dovepress.com/testimonials.php to read real quotes from published authors.

Submit your manuscript here: http://www.dovepress.com/therapeutics-and-clinical-risk-management-journal 